\title{
Adesão em materiais cimentícios: "In-built nanotechnology"
}

\section{(Adhesion in cementitious materials: In-built nanotechnology)}

\author{
H.L.Rossetto ${ }^{l, 2}$, M. F. de Souza ${ }^{2}$, V. C.Pandolfelli ${ }^{l}$ \\ ${ }^{l}$ Departamento de Engenharia de Materiais, Universidade Federal de S. Carlos \\ Rod. Washington Luiz, km 235, C.P. 676, S. Carlos, SP 13565-905 \\ ${ }^{2}$ Instituto de Física de S. Carlos, Universidade de S. Paulo - IFSC-USP, Av. Trabalhador S. Carlense 400, \\ S. Carlos, SP 13566-590 \\ hebert@if.sc.usp.br
}

\begin{abstract}
Resumo
A Engenharia de Materiais propiciou os avanços mais notáveis em termos do desempenho mecânico dos materiais cimentícios nas últimas décadas, por meio das técnicas de conformação e do projeto da microestrutura. Com isso foi demonstrada ser equivocada a idéia de que baixas resistências mecânicas seriam inerentes aos materiais cimentícios. No entanto, pouco ainda se sabe a respeito de um parâmetro físico-químico que poderá nos conduzir a novos avanços: a adesão entre as fases hidratadas. Logo, o objetivo do presente trabalho é investigar a adesão com o intuito de ampliar o entendimento sobre seu papel na resistência mecânica dos materiais cimentícios. Os resultados indicaram que a resistência mecânica desses materiais é governada por moléculas de água confinadas em películas nanométricas entre as superfícies das fases cimentícias hidratadas. Em outras palavras, essa pode ser uma contribuição para tornar viável a nanotecnologia desses materiais por meio de um tema até então pouco explorado: a adesão por água confinada.
\end{abstract}

Palavras-chave: materiais cimentícios, adesão molecular, água confinada.

Abstract

The Materials Engineering afforded the greatest known advances on the mechanical performance of cementitious materials in the latest decades, by casting techniques and microstructural design. Therewith, it was demonstrated to be inadequate the idea that low mechanical strengths should be inherent to cement-based materials. Nevertheless, another promising parameter still remains in the early stages of understanding: the adhesion. Thus, this paper aims to investigate adhesion in order to get an indepth understanding about its role on the mechanical strength of cementitious materials. According to the experimental evidences, the mechanical strength of such materials is ruled by water molecules which are confined in nanolayers by the hydrated surfaces. These results provided helpful insights on in-built nanotechnology able to render high performance materials through a so far little explored subject: the adhesion by confined water.

Keywords: cementitious materials, molecular adhesion, confined water.

\section{INTRODUÇÃO}

Apesar de centenários, os materiais cimentícios ainda são alvo de intensa pesquisa. Devido à importância da resistência mecânica na racionalização de sua utilização, a redução da relação água/cimento $(\mathrm{a} / \mathrm{c})$ foi uma das maneiras pioneiras e mais difundidas de tratar essa questão, graças à diminuição da porosidade. Foi demonstrado que pastas de cimento Portland com relações a/c inferiores a 0,10 podem apresentar resistência à compressão de até $330 \mathrm{MPa}$ após prensagem a $345 \mathrm{MPa}$ durante $1 \mathrm{~h}$ [1]. Posteriormente, foi demonstrado também que a manutenção das baixas relações a/c somada à adição de polímeros solúveis em água permitia conformá-las por técnicas apropriadas às massas plásticas, tais como a prensagem e a extrusão [2]. O bom desempenho mecânico desses materiais cimentícios, com resistência à flexão de 40 a $150 \mathrm{MPa}$, foi atribuído à geração de defeitos menores do que aqueles que resultam das convencionais técnicas de conformação, razão pela qual se cunhou o termo MDF ou "Macro-Defect Free Cements". Isso mostrou ser equívoca a idéia de que a baixa resistência mecânica seria inerente aos materiais cimentícios, e mais tarde culminou no trabalho que privilegiou a dispersão e o empacotamento das partículas, o que resultou em resistência à compressão na faixa de 200 a $600 \mathrm{MPa}$ [3]. Assim se originou o concreto de cimento Portland de maior sucesso na atualidade, chamado Ductal e comercializado pela Lafarge. No entanto, para permitir que os materiais cimentícios ocupem novos nichos de mercado, é preciso entender os detalhes para aprimorar a sua resistência mecânica. Aliás, isso é o que foi destacado, há mais de duas décadas, sobre a necessidade de se investigar a adesão nesses materiais [4]. Desde então, muito pouco foi reportado no meio científico dessa área sobre os avanços nessa direção, com exceção do artigo que especulou sobre a interação das fases hidratadas do cimento Portland com a água [5]. Em geral, o trabalho de Kendall [6] sobre adesão 
molecular foi o que mais chamou a atenção para o tema: o coeficiente de empacotamento $\phi$ e os tamanhos das partículas $\mathrm{D}$, e dos defeitos c, não são os únicos parâmetros a influenciar a resistência mecânica. Sua grande contribuição se traduz pela equação A que ratifica desenvolvimentos prévios e permite inferir também que o trabalho das forças de adesão, $\mathrm{W}$, influencia a resistência mecânica $\sigma_{\mathrm{f}}$. Mas como?

$$
\sigma_{\mathrm{f}}=\frac{15,6 \mathrm{~W} \phi^{4}}{(\mathrm{Dc})^{1 / 2}}
$$

A resposta a essa questão necessita do conhecimento de outras áreas, afinal, sendo a água importante para a obtenção da resistência mecânica então é provável que também desempenhe um papel na adesão. Muitos trabalhos da física básica têm sido dirigidos para o entendimento das complexas propriedades da água, a partir das técnicas de espalhamento de nêutrons e de simulação computacional, principalmente sobre as moléculas de água próximas às superfícies [7, 8]. Todavia, só recentemente é que as primeiras especulações foram levantadas a respeito do poder de adesão dessas moléculas de água confinadas em películas nanométricas (1-3 nm), conhecidas por "água confinada" $[9,10]$. (a)

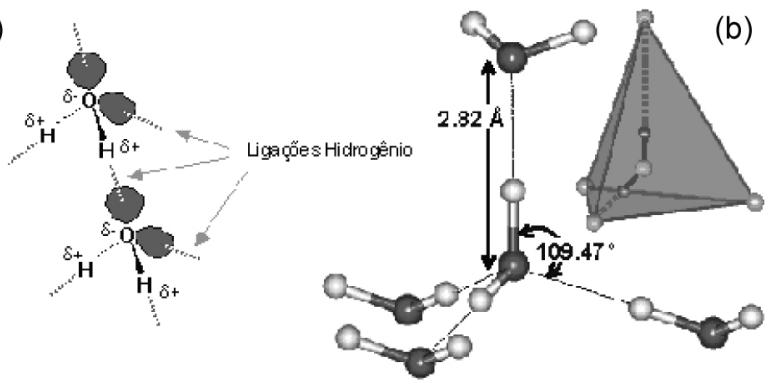

Figura 1: a) Possibilidades de ligações hidrogênio em cada molécula de água: duas ligações como doador $(\delta+)$ e duas como receptor $(\delta-)$; e (b) coordenação tetraedral das moléculas de água [26].

[Figure 1: a) Number of hydrogen bonds for each water molecule: two as donor $(\delta+)$ and two as acceptor $(\delta-) ;(b)$ tetrahedral network of water H-bonds [26].]

$\mathrm{Na}$ verdade, o que garante à água o status de uma substância singular é o número de possíveis ligações hidrogênio para cada molécula. As ligações hidrogênio são formadas quando a eletronegatividade do elemento covalente ao hidrogênio é suficiente para mantê-lo susceptível à interação com outro elemento que disponha de um par de elétrons não-conjugados [11]. Na água, a atração do hidrogênio pelo oxigênio vizinho possui energia cinco vezes maior do que a energia térmica (kT) a $25{ }^{\circ} \mathrm{C}$ e muitas vezes superior à qualquer interação do tipo van der Waals. Aliás, é isso que possibilita à água existir como um líquido nas CNTP e, por conseguinte, a vida como conhecemos.

A Fig. 1 mostra que cada molécula de água é capaz de doar duas ligações hidrogênio e de aceitar outras duas. Com isso, as moléculas de água tendem a se organizar de uma maneira tetraedral: cada átomo de oxigênio é coordenado por quatro outros átomos de oxigênio que apresentam átomos de hidrogênio entre eles. Embora a água líquida mantenha essa tendência de tetraedralidade, sua estrutura é dominada por arranjos locais distorcidos; em média, o número de moléculas vizinhas se situa entre 4,4 e 5,2, enquanto participa de apenas 3,2 a 3,9 ligações hidrogênio [12]. Tais números denotam mecanismos responsáveis por facilitar a relaxação estrutural da água, tais como a coordenação trigonal (ao custo de uma ligação hidrogênio) e as ligações bifurcadas (com o dispêndio de duas ligações) [13]. Ầ medida que a temperatura cai a estruturação tetraedral é restabelecida e o número de defeitos na rede de ligações hidrogênio tende a zero próximo a $228 \mathrm{~K}[14,15]$.

O efeito do confinamento, por sua vez, se assemelha ao da redução da temperatura no que diz respeito à estruturação das moléculas de água. A título de ilustração, o coeficiente de difusão das moléculas de água confinada tem um valor médio de $5,0 \times 10^{-11} \mathrm{~m}^{2} / \mathrm{s}$ ao passo que a água líquida apresenta valor duas ordens de grandeza superior: $2,3 \times 10^{-9} \mathrm{~m}^{2} / \mathrm{s}$. Resultados similares também foram obtidos para parâmetros distintos: Foi reportado que à temperatura ambiente a água confinada se comporta dinamicamente (tempo de residência de ligações hidrogênio) como gelo a $0{ }^{\circ} \mathrm{C}$ [7]; Foi mostrado que sob confinamento a viscosidade da água aumenta sete ordens de grandeza [16]; e foi observado que a água confinada apresenta um tempo de relaxação da ordem de segundos, enquanto seria esperado um tempo da ordem de pico-segundo para a água líquida [10].

Em resumo, em escala nanométrica a água se apresenta como um sólido à temperatura ambiente e pode atuar como um poderoso adesivo. Trabalhos recentes demonstraram a existência de água confinada em materiais cimentícios [17, 18], de modo que o objeto deste trabalho é demonstrar a importância da adesão das fases cimentícias hidratadas pela água confinada, por meio da avaliação da resistência mecânica. Para tanto, será analisada a resistência mecânica em duas situações: na presença de substâncias capazes de estruturar ou de desestruturar as ligações hidrogênio entre as moléculas de água.

\section{MATERIAIS E MÉTODOS}

O cimento Portland responde por $95 \%$ de toda a produção de cimentos e, por essa razão, é o material cimentício de que trata este trabalho (em particular o CPV-ARI com composição em peso de: $64,50 \% \mathrm{C}_{3} \mathrm{~S} ; 3,78 \% \mathrm{C}_{2} \mathrm{~S} ; 11,50 \%$ $\mathrm{C}_{3} \mathrm{~A} ; 7,05 \% \mathrm{C}_{4} \mathrm{AF}$ - sendo $\mathrm{C}=\mathrm{CaO}, \mathrm{S}=\mathrm{SiO}_{2}, \mathrm{~A}=\mathrm{Al}_{2} \mathrm{O}_{3}$, $\mathrm{F}=\mathrm{Fe}_{2} \mathrm{O}_{3}$ - e 7,68\% $\quad \mathrm{CaSO}_{4}$ ). A hidratação do cimento Portland conduz à dissolução das fases anidras e posterior crescimento das fases hidratadas, processo conhecido pelo nome de "dissolução-precipitação". Esse processo termina quando o potencial químico das fases hidratadas se iguala ao da solução. Nesse caso, as moléculas de águas confinadas em nanocamadas pelas superfícies das fases hidratadas que cresceram ao longo desse processo passam a contribuir para a adesão da pasta cimentícia como exposto na introdução. 
De fato, o aumento da fração dessas moléculas de "água confinada" se dá com a compactação, de acordo com a equação A, uma vez que aumenta o número de contatos entre as superfícies. Na prática, esse artifício foi reproduzido neste trabalho pela prensagem do cimento Portland antes ou depois da hidratação, conforme a conveniência para explorar a adesão, a saber: i) desestruturação das moléculas de água por elementos conhecidos como "caotrópicos"; e ii) estruturação das moléculas de água por elementos "cosmotrópicos". Para maiores detalhes, vide referências [19-21].

\section{Elementos caotrópicos}

Os elementos caotrópicos, conhecidos pelo efeito destrutivo à estruturação das moléculas de água, são úteis para demonstrar a importância da adesão quando ela se torna ausente. De maneira geral, os elementos caotrópicos podem ser iônicos ou não-iônicos, no entanto, atuam de maneira a disputar as ligações hidrogênio com as próprias moléculas de água. Os elementos iônicos seguem a série de Hofmeister [22] e são classificados em ordem crescente de desestruturação conforme a Fig. 2. Entre os caotrópicos iônicos utilizados, podem ser citados os hidróxidos de cálcio, lítio e sódio. Entre os não iônicos: dimetilacetamida (DMA), dimetilformamida (DMF) e acetona (DMK).

ESTRUTURAÇÃo

DESESTRUTURAÇÃo

citrato $^{3-}>$ sulfato $^{2-}>$ fosfato ${ }^{2-}>\mathrm{OH}^{-}>\mathrm{F}^{-}>\mathrm{Cl}^{-}>\mathrm{Br}>\mathrm{I}^{-}>\mathrm{NO}_{3}^{-}>\mathrm{ClO}_{4}^{-}$

$\mathrm{N}\left(\mathrm{CH}_{3}\right)_{4}{ }^{+}>\mathrm{NH}_{4}{ }^{+}>\mathrm{Cs}^{+}>\mathrm{Rb}^{+}>\mathrm{K}^{+}>\mathrm{Na}^{+}>\mathrm{Li}^{+}>\mathrm{H}^{+}>\mathrm{Ca}^{2+}>\mathrm{Mg}^{2+}>\mathrm{Al}^{3+}$

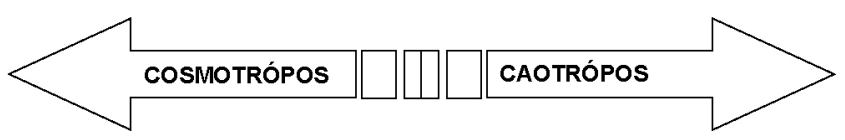

Figura 2: Séries de Hofmeister: ordenação de íons conforme o poder de estruturação (cosmotrópicos) ou desestruturação (caotrópicos) da água confinada (originalmente dirigida à solubilização de proteínas) [26].

[Figure 2: Hofmeister Series: classification of ions according to their structure-maker (kosmotropic) or structure-breaker (chaotropic) effect on H-bonds of confined water (originally for protein solubilization) [26].]

Em todas as experiências com os elementos caotrópicos, os corpos-de-prova foram preparados da mesma forma: i) ao pó de cimento anidro é borrifada água até que a relação $\mathrm{a} / \mathrm{c}=0,15$ seja alcançada; a seguir, ii) esse pó levemente umidificado é prensado sob $20 \mathrm{MPa}$ em molde de aço para resultar em amostras prismáticas com dimensões de $70 \mathrm{x}$ $20 \times 15 \mathrm{~mm}^{3}$; após a extração, iii) as amostras são levadas à uma câmara úmida onde permanecem por $24 \mathrm{~h}$, quando, então iv) passam à cura por imersão em água deionizada à temperatura ambiente por mais 6 dias. Logo, no sétimo dia as amostras são secas a $30^{\circ} \mathrm{C}$ por $24 \mathrm{~h}$ e separadas em grupos, cada qual contendo pelo menos cinco unidades. Um dos grupos é mantido para referência enquanto os demais são novamente imersos por $24 \mathrm{~h}$ em soluções contendo os diferentes elementos caotrópicos utilizados neste trabalho. Por fim, ao final desse período são secos mais uma vez a $30{ }^{\circ} \mathrm{C}$ por $24 \mathrm{~h}$ para avaliação da resistência mecânica à flexão em 3-pontos (ASTM C-1161, L=45 mm) em equipamento universal (MTS 810). Esse procedimento evita influências sobre a microestrutura do material (conforme as micrografias de microscopia eletrônica de varredura omitidas neste trabalho), de modo a permitir a correlação direta entre adesão e resistência mecânica (equação A).

\section{Elementos cosmotrópicos}

Apesar do item anterior objetivar a demonstração da importância da adesão sobre a resistência mecânica dos materiais cimentícios, a questão que permanece é se há a possibilidade de elevá-la pelo aumento da adesão. Para tanto, os elementos "cosmotrópicos", assim conhecidos pela capacidade de estruturar as moléculas de água, podem supostamente indicar alternativas. Entre os cosmotrópicos utilizados, podem ser citados aqueles de natureza iônica, tal como o sal de citrato de amônio, bem como aqueles de natureza não-iônica, como açúcares e aminoácidos. Estes últimos, principalmente, são bem conhecidos pelo drástico efeito sobre o retardo da pega do cimento Portland, o que exigiu um novo procedimento para o preparo dos corposde-prova. Em geral, o procedimento consistiu em realizar a prensagem do pó como acima descrito em (i) somente após 7 dias do molhamento. Nesse ínterim, o pó cimentício se hidratou no interior de recipientes plásticos selados (conforme os difratogramas de raios $\mathrm{X}$ aqui não mostrados). No entanto, a livre hidratação do cimento Portland isenta de restrições o crescimento das fases hidratadas [23], o que, por conseguinte, dificulta o posterior empacotamento desse pó pré-hidratado. Com isso, a continuidade do procedimento segue como: (a) molhamento do pó cimentício pré-hidratado com soluções aquosas dos elementos cosmotrópicos utilizados neste trabalho (exceto amostras referência 2 que foram molhadas apenas por água); e (b) sua prensagem a 100 MPa em molde de aço para obtenção de amostras prismáticas com dimensões similares àquelas do item anterior. Os grupos de amostras obtidos sofreram os mesmos procedimentos de secagem e avaliação mecânica como também descritos anteriormente.

\section{Caracterização físico-química}

Além das já citadas técnicas de difração por raios X e de microscopia eletrônica de varredura, duas outras foram muito utilizadas para a avaliação de parâmetros físico-químicos de interesse ao trabalho: a ressonância magnética nuclear do isótopo natural do elemento silício $\left({ }^{29} \mathrm{Si}\right.$ MAS-NMR, vide $[24,25]$ para detalhes experimentais), para mensurar o grau de hidratação das amostras cimentícias; e o teste de De Nouy, para mensurar o efeito das substâncias sobre a tensão superficial das soluções aquosas. 


\section{RESULTADOS E DISCUSSÃO}

A Fig. 3 mostra os resultados de ensaios mecânicos à flexão em 3-pontos das amostras expostas aos elementos caotrópicos iônicos. Embora todos os grupos de amostras tenham apresentado massas específicas $\left(\rho=2,24 \pm 0,02 \mathrm{~g} / \mathrm{cm}^{3}\right)$ e graus de hidratação $(x=42 \pm 3 \%)$, avaliados pela técnica de ${ }^{29} \mathrm{Si}$ MAS-NMR, similares, o mesmo não pode ser dito sobre a resistência mecânica $\left(\sigma_{\mathrm{B}}\right)$. Todos os grupos de amostras submetidos aos elementos caotrópicos iônicos sofreram redução na resistência à flexão quando comparada à da amostra de referência $1\left(\sigma_{B}=23 \pm 3 \mathrm{MPa}\right)$. No entanto, essa redução da resistência mecânica mostra uma forte correlação com o poder de desestruturação dos íons, em detrimento do pH da solução. Com o intuito de facilitar a comparação, todos os elementos catiônicos $\left(\mathrm{Ca}^{2+}, \mathrm{Li}^{+}\right.$e $\left.\mathrm{Na}^{+}\right)$foram acompanhados pelo mesmo ânion, o íon hidroxila $\left(\mathrm{OH}^{-}\right.$ ). Nesse caso, observou-se que a intensidade na queda da resistência mecânica seguiu a ordem crescente da Série de Hofmeister para cations: $\mathrm{Ca}^{2+}>\mathrm{Li}^{+} \approx \mathrm{Na}^{+}$(Fig. 2). Além disso, o aumento da concentração iônica em solução acentuou ainda mais a redução da resistência mecânica.

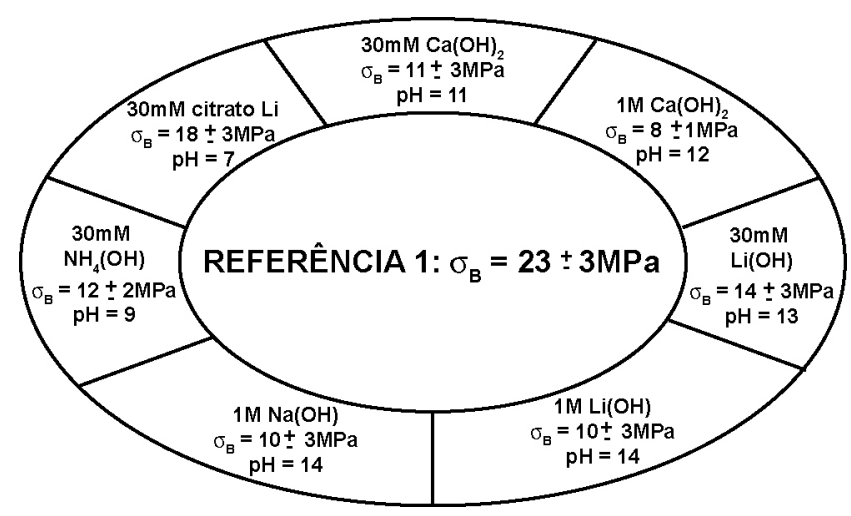

Figura 3: Resultados da resistência mecânica à flexão em 3-pontos dos grupos de amostras expostas aos diferentes elementos caotrópicos iônicos. Em destaque, a resistência mecânica das amostras de referência 1 para as devidas comparações.

[Figure 3: Results for 3-point bending strength of cementitious plates after exposing to different chaotropic ionic solutions. The bending strength for the reference sample 1 is highlighted (center) in order to draw comparisons.]

Mantido o elemento caotrópico aniônico $\left(\mathrm{OH}^{-}\right)$, porém agora acompanhado de um cátion cosmotrópico em solução, o íon amônio $\left(\mathrm{NH}_{4}^{+}\right)$, o resultado mostrou que o efeito destrutivo do ânion suplantou o efeito estruturante do cátion, o que corrobora com a literatura no assunto [26]. Na verdade, os ânions possuem maior atração por ligações hidrogênio, o que se comprovou por meio dos experimentos quando o ânion utilizado foi o citrato ${ }^{3+}$, um elemento cosmotrópico. Nesse caso, mesmo na presença de um caotrópico com razoável poder de desestruturação das moléculas de água, o íon $\mathrm{Li}^{+}$, a queda na resistência mecânica da amostra cimentícia foi pouco expressiva ( $18 \pm 3 \mathrm{MPa}$ contra $23 \pm 3 \mathrm{MPa}$ da amostra de referência 1).

As experiências com elementos caotrópicos não-iônicos - a saber: acetona (DMK), dimetilacetamida (DMA) e dimetilformamida (DMF) - também reproduziram os mesmos resultados obtidos com os caotrópicos iônicos: redução acentuada da resistência mecânica das amostras cimentícias, como mostra a Tabela I. Em geral, os caotrópicos não-iônicos supracitados possuem um grupo carbonil em comum, ou seja, $\mathrm{C}=\mathrm{O}$, cujo efeito de desestruturação provém da maior afinidade das ligações $\mathrm{C}=\mathrm{O} \cdots \mathrm{HOH}$ relativa às ligações hidrogênio entre moléculas de água, $\mathrm{HOH} \cdots \mathrm{HOH}$. No entanto, a redução da resistência mecânica também pode ser analisada por outro ângulo.

Tabela I - Resistência à flexão em 3-pontos $\left(\sigma_{B}\right)$ de grupos de amostras expostas às soluções aquosas de elementos caotrópicos não-iônicos; constante dielétrica dessas soluções (k); e razão entre tensões superficiais das soluções e da água deionizada $\left(\gamma_{\mathrm{soL}} / \gamma_{\mathrm{w}}\right)$.

[Table I - 3-point bending strength $\left(\sigma_{B}\right)$ of cement plates after exposing to non-ionic chaotropic solutions; dielectric constant (k) for such substances; and ratio between surface tension of each solution to that of deionized water $\left(\gamma_{S O L} / \gamma_{W}\right)$.]

\begin{tabular}{lccc}
\hline Amostras & $\sigma_{\mathrm{B}}(\mathrm{MPa})$ & $\mathrm{k}$ & $\gamma_{\mathrm{SOL}} / \gamma_{\mathrm{w}}$ \\
\hline $\begin{array}{l}\text { Referência 1 } \\
\text { (imersão em água) }\end{array}$ & $23 \pm 3$ & 80 & 1,00 \\
$\begin{array}{l}\text { Imersão em solução de } \\
\text { DMF (30 mmol/L) }\end{array}$ & $12 \pm 4$ & 37 & 0,98 \\
$\begin{array}{l}\text { Imersão em solução } \\
\text { de DMA (1 mol/L) }\end{array}$ & $10 \pm 3$ & 38 & 0,87 \\
$\begin{array}{l}\text { Imersão em solução de } \\
\text { DMK (1 mol/L) }\end{array}$ & $9 \pm 2$ & 21 & 0,75 \\
\hline
\end{tabular}

Note que as constantes dielétricas das soluções caotrópicas ficaram sempre abaixo da constante dielétrica da água. Se a força de adesão entre fases hidratadas fossem predominantemente do tipo van der Waals, então seria esperado que uma redução da constante dielétrica do meio provocasse um aumento na atração entre as superfícies, em outras palavras, um aumento da adesão entre elas. Pela equação $\mathrm{A}$, supõe-se que um aumento da adesão implique num aumento da resistência mecânica, o que, de fato, não foi verificado na prática. Isso mostra a impossibilidade da predominância das forças de van der Waals sobre a adesão das fases hidratadas do cimento Portland [27]. Por outro lado, se fosse a adesão dominada por forças do tipo capilar, uma queda na tensão superficial do líquido deveria da mesma forma conduzir à queda na resistência mecânica da amostra cimentícia [12]. O resultado obtido com a solução de DMF mostrou uma forte queda na resistência mecânica 
para uma variação pouco significativa da tensão superficial do líquido em relação ao da amostra de referência $1\left(\gamma_{\text {soL }} / \gamma_{\mathrm{w}}\right)$. As demais soluções forneceram resultados que linearmente não se correlacionam à queda relativa na tensão superficial do líquido. Essa é mais uma evidência de que as ligações hidrogênio, afetadas pelo efeito de desestruturação dos elementos caotrópicos, governam as forças de adesão entre as superfícies das fases cimentícias hidratadas.

Para entender a influência desses elementos caotrópicos sobre a resistência mecânica das amostras cimentícias, é preciso recorrer à Fig. 4, que configura o contato entre as superfícies hidratadas. De fato, o contato ocorre em poucos pontos discretos ao longo de um raio de tangência entre as superfícies hidratadas e, nesses pontos as moléculas de água confinadas se comportam como uma fase vítrea que adere tais superfícies. As superfícies cimentícias podem estruturar as moléculas de água a uma distância de até $1 \mathrm{~nm}$, o que indica que duas superfícies distantes $2 \mathrm{~nm}$ uma da outra, isto é, aproximadamente seis camadas de moléculas de água, poderiam se beneficiar da adesão conferida por água confinada [17]. Vale lembrar que dentro dessas camadas as moléculas de água estabelecem ligações hidrogênio entre si, cada qual com um determinado tempo de residência. Quanto maior a proximidade às superfícies, maior a estabilidade das ligações, de modo que as superfícies ligadas apenas por uma ou duas moléculas de água são dificilmente separadas. Essa é a razão pela qual a resistência mecânica nunca se anula. Porém, as superfícies que se aderem por meio de camadas com seis a oito moléculas de água são mais susceptíveis à disputa pelas suas ligações hidrogênio. Quando isso ocorre, como, por exemplo, por influência dos elementos caotrópicos, essa fração de água confinada que contribuía para a adesão das superfícies torna-se inativa. Em outras palavras, tais moléculas passam a solvatar os caotropos ao invés de se manterem sob a influência das superfícies, com consequiências sobre a adesão e a resistência mecânica das amostras cimentícias, já que a microestrutura permaneceu inalterada.

Com isso, a questão que permanece é como utilizar esse conhecimento em prol do aumento da adesão e, por conseguinte, da resistência mecânica de materiais cimentícios. Naturalmente, uma alternativa é o estudo da influência dos elementos cosmotrópicos, conhecidos pela

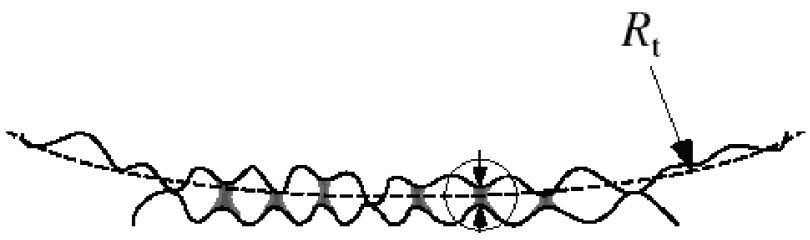

Figura 4: Representação do contato entre superfícies hidratadas. Destaque para o espaçamento heterogêneo entre as superfícies ao longo de uma suposta tangência que, de fato, ocorre em poucos pontos discretos [28].

[Figure 4: Contact profiles for two hydrated surfaces. Notice that the gap between such surfaces is irregular along of a supposed tangency which, indeed, happens through only a few discrete points [28].] estruturação das moléculas de água confinada. Na biologia, algumas enzimas possuem capacidade para realizar ligações hidrogênio com moléculas de água de modo a permitir que duas superfícies se adiram mesmo em distâncias superiores àquelas em que as moléculas de água são capazes de se estruturar por si próprias [11]. Em outras palavras, existem substâncias capazes de desempenhar o papel de andaimes entre superfícies hidratadas. Entre aquelas com capacidade para tanto, foram utilizadas: a sacarose, a trealose, a prolina e o citrato de amônio. A Tabela II traz resultados da resistência mecânica à flexão em 3-pontos para grupos de amostras em que os elementos cosmotrópicos acima foram utilizados, além da amostra referência 2 para qual se utilizou apenas água como líquido de molhamento do pó cimentício "préhidratado".

Tabela II - Resultados para amostras preparadas com cimento pré-hidratado molhado por soluções aquosas com elementos adesivos na relação de $\mathrm{a} / \mathrm{c}=0,10$ e prensado a $100 \mathrm{MPa}$ por 10 min: resistência mecânica à flexão em 3-pontos $\left(\sigma_{\mathrm{B}}\right)$ e massa específica $(\rho)$.

[Table II - Apparent density ( $\rho$ ) and 3-point bending strength $\left(\sigma_{B}\right)$ for the cementitious samples made of pre-hydrated cement slightly moistened $(w / c=0.10)$ by aqueous solutions of adhesive substances and uniaxially pressed (100 MPa for $10 \mathrm{~min})$.

\begin{tabular}{lcc}
\hline Elemento Adesivo & $\sigma_{\mathrm{B}}(\mathrm{MPa})$ & $\rho\left(\mathrm{g} / \mathrm{cm}^{3}\right)$ \\
\hline $\begin{array}{l}\text { Referência 2 (água deionizada, } \\
\text { PM=18 g/mol) }\end{array}$ & $8,0 \pm 1,3$ & $1,86 \pm 0,02$ \\
$\begin{array}{l}\text { Citrato de amônio } \\
\text { (PM=226 g/mol; solução 0,5 M) }\end{array}$ & $7,6 \pm 1,0$ & $1,82 \pm 0,02$ \\
$\begin{array}{l}\text { Trealose (PM=378 g/mol; } \\
\text { solução 0,5 M) }\end{array}$ & $6,6 \pm 0,8$ & $1,88 \pm 0,01$ \\
$\begin{array}{l}\text { Sacarose (PM=342 g/mol; } \\
\text { solução 0,5 M) }\end{array}$ & $12,7 \pm 1,5$ & $1,92 \pm 0,01$ \\
$\begin{array}{l}\text { L-Prolina (PM=115 g/mol; } \\
\text { solução 0,5 M) }\end{array}$ & $12,4 \pm 1,2$ & $1,87 \pm 0,01$ \\
\hline
\end{tabular}

Primeiramente, é preciso ressaltar que o molhamento do pó cimentício pré-hidratado por água ou por suas soluções não induz a uma mudança significativa no grau de hidratação, como se pode comparar pelos resultados das Figs. 5b e 5c. Além disso, as variações de massa específica entre grupos de amostras da Tabela II foram muito pequenas para impedir a comparação de suas resistências mecânicas diretamente com a adesão atuante. Com isso, o primeiro resultado a ser discutido é o da amostra de referência 2 . Por se tratar de uma amostra em que a hidratação não foi necessária para a obtenção da resistência mecânica, e cujo valor se assemelha aos de amostras submetidas aos mais severos elementos caotrópicos, como o $\mathrm{Ca}^{2+}$, é provável que a elevada compactação tenha logrado êxito em confinar pelo 

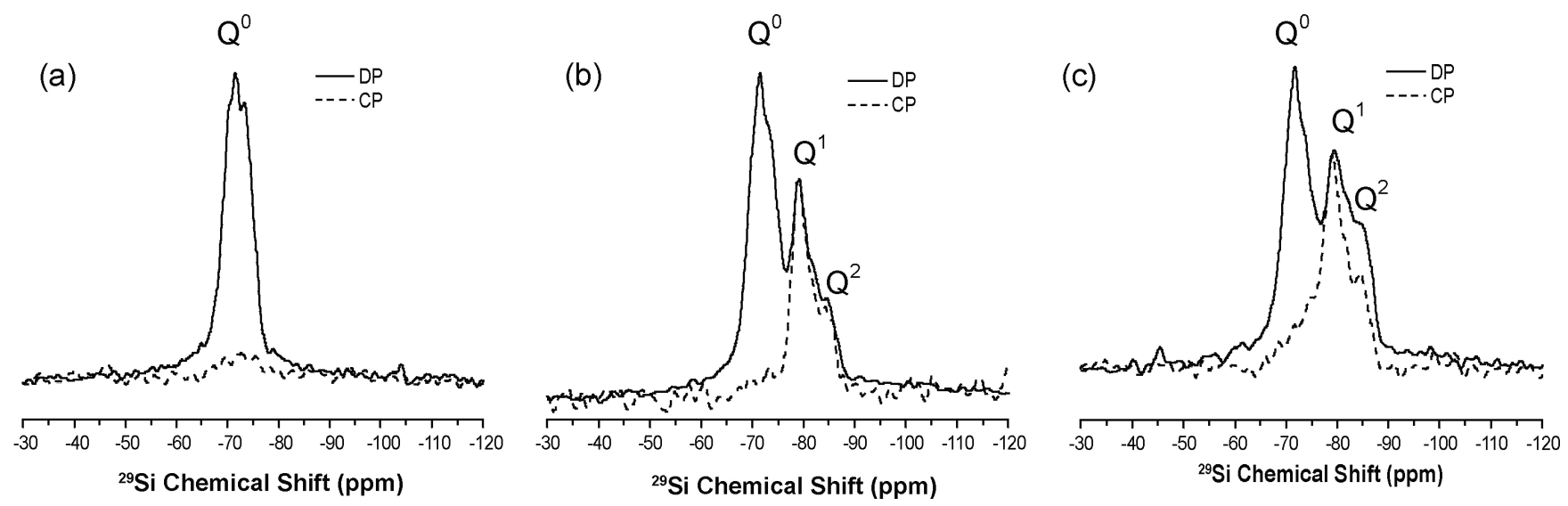

Figura 5: Espectros de ressonância magnética nuclear ( ${ }^{29}$ Si MAS-NMR) de amostras cimentícias distintas: (a) cimento Portland anidro $(\mathrm{x}=0 \%)$; (b) cimento após 7 dias do molhamento com água na relação $(\mathrm{a} / \mathrm{c})=0,15$, sem prensagem, dito pó de cimento "pré-hidratado" $(\mathrm{x}=45 \pm 5 \%)$; (c) pó de cimento pré-hidratado após novo molhamento com água na relação $(\mathrm{a} / \mathrm{c})=0,10$ e prensagem a $100 \mathrm{MPa}(\mathrm{x}=$ $49 \pm 3 \%$ ). Curvas: DP (linha contínua) - polarização direta do ${ }^{29} \mathrm{Si}$ evidenciando os picos de $\mathrm{Q}^{0}\left(\mathrm{SiO}_{4}\right), \mathrm{Q}^{1}\left(\mathrm{HOSiO}_{3}\right)$ e $\mathrm{Q}^{2}\left((\mathrm{OH})_{2} \mathrm{SiO}_{2}\right)$ a partir dos quais se determina o grau de hidratação $(\mathrm{x})$ da amostra; e CP (linha tracejada) - polarização cruzada entre ${ }^{29} \mathrm{Si}-{ }^{1} \mathrm{H}$, evidenciando os picos das fases cimentícias hidratadas $[23,29]$.

[Figure 5: ${ }^{29} \mathrm{Si}-\mathrm{NMR}-\mathrm{MAS}$ results for: (a) anhydrous Portland cement powder; (b) pre-hydrated Portland cement powder (w/c=0.15), or pre-hydrated starting material; (c) sample prepared by the compaction (100 MPa for 10 min) of the starting material sprayed with water (10wt\% relative to the starting material). Solid lines represent the Direct Polarization of ${ }^{29} \mathrm{Si}(D P)$, whereas the dashed ones (Cross Polarization of ${ }^{1} \mathrm{H}_{-}^{29} \mathrm{Si}, \mathrm{CP}$ ) represent hydrated sites. DP curves can distinguish the CSH populations (i.e. $Q^{0}, Q^{1}$, and $\left.Q^{2}\right)$ and, hence, the degree of hydration $(x)$ of the sample; whereas CP illustrates which populations are the hydrated ones $\left(Q^{I}\right.$ and $\left.\left.Q^{2}\right)[23,29].\right]$

menos uma ou duas moléculas de água entre alguns pontos discretos das superfícies pré-hidratadas. Diante disso, é possível avaliar que o efeito do único cosmotrópico iônico utilizado como adesivo, o citrato de amônio, não tenha sido eficaz para reproduzir a expectativa enunciada no parágrafo anterior. Na verdade, os cosmotrópicos iônicos são, algumas vezes, denominados por "anti-caotrópicos" justamente porque seus campos elétricos não são fortes o bastante para solvatar um número expressivo de moléculas de água [26].

Quanto aos cosmotrópicos não-iônicos, a trealose, apesar de ser considerada como um dos mais importantes elementos dessa classe, não surtiu melhorias sobre a adesão das amostras cimentícias. Contrariamente, a resistência mecânica obtida ficou ligeiramente inferior àquela da amostra de referência 2. Na verdade, a trealose estrutura fortemente as moléculas de água, porém interfere na tetraedralidade das ligações hidrogênio: a estrutura local possui grande número de moléculas de água que realizam apenas uma ligação hidrogênio com a trealose e ficam impossibilitadas de realizar ligações hidrogênio com outras moléculas de água ou até mesmo com moléculas de água orientadas por outras moléculas de trealose. Tal estrutura local é considerada "mais densa" do que a estrutura tetraedral [26].

Por outro lado, a sacarose tende a orientar as moléculas de água segundo uma estrutura localmente "menos densa". Além disso, cada radical $\mathrm{OH}$ da sacarose pode realizar em média duas ligações hidrogênio com moléculas de água [30], o que aumenta suas chances de atuar como um "andaime" entre as superfícies hidratadas. Isso se reflete num aumento da adesão com conseqüente elevação da resistência mecânica das amostras cimentícias assim aderidas relativa à amostra referência 2, como mostra a Tabela II. O mesmo ocorre com a prolina, que, além disso, goza de uma combinação capaz de aumentar a intensidade das forças resultantes das ligações hidrogênio: um excesso na densidade de elétrons do elemento receptor [11]. Portanto, não se trata apenas da capacidade que o elemento cosmotrópico tem para realizar ligações hidrogênio, mas também a configuração local e eletrônica que resulta da estruturação das moléculas de água que ele proporciona.

\section{CONCLUSÃO}

O objetivo deste trabalho foi demonstrar a importância da adesão das fases cimentícias hidratadas pela água confinada.Na prática, isso foi realizado de modo indireto pela avaliação da resistência mecânica de amostras cimentícia depois de uma propositada interação com substâncias capazes ora de desestruturar, ora de estruturar as moléculas de água confinada. Como demonstrado pelos experimentos com elementos caotrópicos, uma elevada fração da água confinada, provavelmente aquela composta por camadas com mais de duas moléculas de água, é susceptível à disputa por suas ligações hidrogênio, enquanto o restante se mantém incólume à presença desses elementos. Isso é um indício de que o processo de hidratação foi responsável por reduzir a separação das superfícies cimentícias, pelo crescimento das fases hidratadas que confinam moléculas de água em nanocamadas. Mas, a hidratação não é totalmente responsável pela resistência pela resistência mecânica dos 
materiais cimentícios. Como demonstrado neste trabalho, mesmo pós cimentícios pré-hidratados podem gozar de considerável resistência mecânica quando suas superfícies, novamente molhadas por água, são aproximadas o bastante para confinar moléculas de água em nanocamadas. Nessas condições, a água confinada se comporta com um sólido à temperatura ambiente e então permite aderir duas superfícies que com ela possam realizar ligações hidrogênio. Neste caso, algumas substâncias cosmotrópicas são capazes de manter a estabilidade dessas ligações mesmo quando tais superfícies se encontram separadas por distâncias maiores do que aquelas em que moléculas de água se estruturam por si próprias.

Em resumo, os materiais cimentícios gozam de uma "nanotecnologia" que deriva de sua capacidade de confinar moléculas de água em nanocamadas entre as superfícies hidratadas, ao que chamamos de "in-built nanotechnology". Se melhor aproveitado, esse potencial pode se tornar mais promissor, em termos de resistência mecânica, do que o projeto da microestrutura com a adição de nanopartículas.

\section{AGRADECIMENTOS}

Ao Prof. Dr.Eduardo Azevedo (IFSC-USP) pelo precioso auxílio aos ensaios com a técnica de ressonância magnética nuclear, e à FAPESP e ao CNPq, pelas bolsas de fomento científico concedidas ao primeiro autor deste trabalho, Procs. 02/10492-3 e 151329/2007-9, respectivamente.

\section{REFERÊNCIAS}

[1] D. M. Roy, G. R. Gouda, Cem. Concr. Res. 3, 6 (1973) 807.

[2] J. D. Birchall, A. J. Howard, K. Kendall, Nature 289, 5796 (1981) 388.

[3] P. Richard, M. Cheyrezy, Cem. Concr. Res. 25, 7 (1995) 1501.

[4] D. D. Double, Nature 289, 5796 (1981) 348.

[5] R. J. Pellenq, H. van Damme, MRS Bulletin 29, 5 (2004) 319.

[6] K. Kendall, Molecular Adhesion and its Applications: the Sticky Universe, Kluwer Academic-Plenum Publ., New York, EUA (2001) p. 429.

[7] J. Teixeira, J.-M. Zanotti, M.-C. Bellissent-Funel, S.-H. Chen, Physica B 234-236 (1997) 370.

[8] L. J. Michot, F. Villiéras, M. François, I. Bihannic, M. Pelletier, J.-M. Cases, Geoscience 334, 9 (2002) 611.

[9] C. Yang, U. Tartaglino, B. N. J. Persson, Cond. Mat.
(2006) 0608098.

[10] K. B. Jinesh, J. W. M. Frenken, Phys. Rev. Lett. 96 (2006) 166103.

[11] G. A. Jeffrey, An Introduction to Hydrogen Bonding, Oxford University Press, Inc., New York, EUA (1997) p. 303.

[12] J. Israelachvili, Intermolecular and Surface Forces, $2^{\text {nd }}$ Ed., Academic Press, Inc., London, UK (1992) p. 450.

[13] S. Sastry, Nature 398, 6727 (1999) 467.

[14] R. J. Speedy, C. A. Angell, J. Chem. Phys. 65, 3 (1976) 851.

[15] K. Ito, C. T. Moynihan, C. A. Angell, Nature 398, 6727 (1999) 492.

[16] R. C. Major, J. E. Houston, M. J. McGrath, J. I. Siepmann, X. -Y. Zhu, Phys. Rev. Lett. 96 (2006) 177803.

[17] A. G. Kalinichev, J. Wang, R. J. Kirkpatrick, Cem. Concr. Res. 37, 3 (2007) 337.

[18] I. Padureanu, D. Aranghel, G. Rotarescu, F. Dragolici, C. Turcanu, Z. A. Kozlov, V. A. Semenov, Rom. J. Phys. 50, 5-6 (2005) 561.

[19] H. L. Rossetto, M. F. de Souza, V. C. Pandolfelli, J. Mater. Sci. Lett. (2008) submetido.

[20] H. L. Rossetto, M. F. de Souza, V. C. Pandolfelli, Mater. Res. 11, 2 (2008) 183-185.

[21] H. L. Rossetto, "Contribuições para a Ciência e a Engenharia dos Materiais Cimentícios: Processamento, Durabilidade e Resistência Mecânica", Tese de Doutorado em Ciência e Engenharia dos Materiais, Instituto de Física de S. Carlos, USP, S. Carlos, SP (2007) p. 124.

[22] V. A. Parsegian, Nature 378 (1995) 335.

[23] L. D. Mitchell, M. Prica, J. D. Birchall, J. Mater. Sci. 31, 16 (1996) 4207.

[24] G. Engelhardt, High-Resolution Solid-State NMR of Silicates and Zeolites, John Wiley and Sons, New York, EUA (1987).

[25] E. Lippmaa, M. Mägi, M. Tarmak, Cem. Concr. Res. 12 (1982) 597.

[26] M. Chaplin, Water structure and behavior: www.lsbu. ac.uk/water/hofmeist.html, acesso em 12/02/2008.

[27] S. R. Raghavan, H. J. Walls, S. A. Khan, Langmuir 16, 21 (2000) 7920.

[28] S. P. Jarvis, in M. Rosoff (Ed.), Nano-Surface Chemistry, Marcel Dekker, Inc., New York, EUA (2002) 7-58.

[29] H. Zanni, in Proc. 11 ${ }^{\text {th }}$ Int. Cong. Chem. Cement, Durban, África do Sul (2003).

[30] T. Suzuki, Phys. Chem. Chem. Phys. 10 (2008) 96.

(Rec. 25/03/2008, Ac. 16/05/2008) 